\title{
RETINAL TOXICITY OF INTRAVITREAL TRIAMCINOLONE ACETONIDE
}

\section{A Morphological Study}

\author{
SEUNG-YOUNG YU, MD, FRANCISCO MAX DAMICO, MD, \\ FRANCESCO VIOLA, MD, DONALD J. D'AMICO, MD, \\ LUCY H. YOUNG, MD, PHD
}

Purpose: To evaluate the morphologic effects of intravitreal triamcinolone acetonide (TA) on rabbit retina.

Methods: Intravitreal injections of $0.5 \mathrm{mg}, 1 \mathrm{mg}, 4 \mathrm{mg}, 8 \mathrm{mg}$, and $20 \mathrm{mg}$ of TA (Kenalog-40; Bristol-Myers Squibb, Princeton, NJ) in $0.1 \mathrm{~mL}$ were given to pigmented rabbits. For control, $0.1 \mathrm{~mL}$ of TA vehicle and saline were injected. Animals were killed on day 14, and retinas were analyzed by light as well as electron microscopy.

Results: No ophthalmoscopic change was found. Eyes injected with $0.5 \mathrm{mg}$ and $1 \mathrm{mg}$ of TA did not have morphologic abnormality. Eyes injected with $4 \mathrm{mg}, 8 \mathrm{mg}$, and $20 \mathrm{mg}$ showed destruction of photoreceptor outer segments and migration of macrophage-like cells in the subretinal space. Eyes injected with $20 \mathrm{mg}$ showed more extensive damage and increased pigment granules in the retinal pigment epithelium cells with large oil droplets in the cytoplasm. Electron microscopy also showed loss of photoreceptor/retinal pigment epithelium interdigitations. Eyes injected with vehicle or saline did not show morphologic changes.

Conclusion: Single intravitreal injection of $0.5 \mathrm{mg}$ or $1 \mathrm{mg}$ of TA did not produce morphologic retinal changes in pigmented rabbits. However, injections of $4 \mathrm{mg}, 8 \mathrm{mg}$, and $20 \mathrm{mg}$ of TA produced outer retina toxic effects. These findings suggest that long-term retinal toxicity studies should be carried out, using single and repeated injections before this therapy becomes more widely used.

RETINA 26:531-536, 2006

$I^{n}$ ntravitreal injection of triamcinolone acetonide (TA) has been largely used as an alternative in the treatment of macular edema secondary to diabetes,

From the Retina Service, Massachusetts Eye and Ear Infirmary, Harvard Medical School, Boston, Massachusetts.

Supported in part by the Vitreoretinal Research Fund (to D.J. D'Amico)

Presented in part at the 2004 Association for Research in Vision and Ophthalmology Meeting, Ft. Lauderdale, FL, and the 2004 Retina Society Annual Meeting, Baltimore, MD, Sept. 30 to Oct. 3, 2004.

The authors do not have any proprietary interest in this study.

Reprint requests: Lucy H. Young, MD, PhD, Massachusetts Eye and Ear Infirmary, 243 Charles Street, Boston, MA 02114; e-mail: lhyoung@meei.harvard.edu retinal vascular occlusion, uveitis, and Irvine-Gass syndrome. ${ }^{1-5}$ In addition, TA has been proposed as adjunctive treatment for exudative age-related macular degeneration, proliferative vitreoretinopathy, and uveitis because of its antiangiogenic, antiproliferative, and antiinflammatory properties. ${ }^{6-9}$

Drug delivery into the posterior segment of the eye alleviates some issues, such as intraocular penetration and bioavailability, and can lead to improved therapeutic effect by increasing the intraocular drug concentration. ${ }^{10,11}$ However, it can be associated with a higher risk of local toxicity. The ocular side effects of topical steroids are well known and include posterior 
subcapsular cataract and elevation of ocular pressure. ${ }^{12}$ More recently, several case series on complications after intravitreal injection of TA have been reported, including ocular hypertension and infectious or sterile endophthalmitis. ${ }^{13-17}$ However, there is little information on the effect of TA on the retina.

Previous animal studies did not show retinal toxicity after intravitreal injection of up to $4 \mathrm{mg}$ of TA, ${ }^{18-21}$ but even higher doses have been used clinically. ${ }^{1-4,6-9}$ The purpose of this study was to evaluate morphologic changes on pigmented rabbit retina caused by intravitreal injection of TA (Kenalog-40; Bristol-Myers Squibb, Princeton, NJ) at concentrations used in clinical practice.

\section{Methods}

\section{Animals}

Twenty-four Dutch Belted rabbits (weight, $2-3 \mathrm{~kg}$ ) were used in this study. All animals were treated in accordance with the Association for Research in Vision and Ophthalmology Statement for the Use of Animals in Ophthalmic and Vision Research, and the experiments were approved by the Animal Care Committee of the Massachusetts Eye and Ear Infirmary (Boston, MA). Animals were anesthetized with intramuscular injection of $50 \mathrm{mg} / \mathrm{kg}$ ketamine hydrochloride and $5 \mathrm{mg} / \mathrm{kg}$ xylazine hydrochloride, and pupils were dilated with topical $2.5 \%$ phenylephrine. Topical anesthesia was achieved with $0.5 \%$ proparacaine. Animals were divided in 7 groups: $0.5 \mathrm{mg}$ of TA ( 3 eyes), $1 \mathrm{mg}$ of TA (3 eyes), $4 \mathrm{mg}$ of TA ( 4 eyes), $8 \mathrm{mg}$ of TA (4 eyes), $20 \mathrm{mg}$ of TA (4 eyes), vehicle ( 2 eyes), and saline (4 eyes). Contralateral eyes were left untouched.

\section{TA Preparation}

TA (Kenalog-40 [40 mg/mL TA, 0.99\% (w/v) benzyl alcohol, $0.75 \%$ carboxymethylcellulose sodium, and $0.04 \%$ polysorbate 80 ]; Bristol-Myers Squibb) was used. The drug was prepared in a $1-\mathrm{mL}$ tuberculin syringe. A volume of $0.1 \mathrm{~mL}$ was injected in the eye.

For $0.5-\mathrm{mg}$ and $1-\mathrm{mg}$ injections, $0.1 \mathrm{~mL}$ of the original suspension was diluted with $0.7 \mathrm{~mL}$ and 0.3 $\mathrm{mL}$ of sterile saline for injection, respectively, and 0.1 $\mathrm{mL}$ of the new suspension was injected into the vitreous. For 4-mg injections, $0.1 \mathrm{~mL}$ of the original suspension was injected. For 8 -mg and $20-\mathrm{mg}$ injections, $1 \mathrm{~mL}$ of the original suspension was drawn up into the syringe and kept in a vertical position with the needle turned up for 30 minutes, until TA settled down. Then, $0.5 \mathrm{~mL}$ and $0.8 \mathrm{~mL}$ of the supernatant (vehicle), respectively, was discarded. The remaining suspension was mixed, and $0.1 \mathrm{~mL}$ was injected into the vitreous. Vehicle was prepared as described above for 8 -mg and 20-mg injections.

\section{Intravitreal Injection}

Before injections, eyes were dilated, and paracentesis with removal of $0.1 \mathrm{~mL}$ of aqueous humor was performed using a $1-\mathrm{mL}$ syringe with a 30 -gauge needle, to avoid an increase in intraocular pressure. Intravitreal injection of $0.1 \mathrm{~mL}$ of solution was performed with a $1-\mathrm{mL}$ syringe with a 27 -gauge needle, slowly and under direct observation with a stereoscopic microscope, directed to the center of the vitreous cavity.

\section{Ocular and Histologic Examination}

Animals underwent slit-lamp biomicroscopy, indirect ophthalmoscopy, and fundus photography before and immediately after injection and on days 1, 3, 7, and 14. All animals were killed on day 14 with intravenous injection of phenobarbital sodium solution (Fatal-Plus; Vortech Pharmaceuticals, Dearborn, MI). Immediately after death, eyes were enucleated, the anterior segment with the lens was removed, and the posterior segment was fixed in 50\% Karnovsky (Electron Microscopy Sciences, Fort Washington, PA) for 24 hours. After fixation, $5 \times 5$-mm pieces of the inferior midperipheral posterior segment (retina/cho$\mathrm{roid} / \mathrm{sclera}$ ) were processed for light microscopy (BHS System; Olympus Optical, Tokyo, Japan) and transmission electron microscopy (Philips 410 EM; Philips Electron Optics, Eindhoven, Holland). Light microscopy sections were stained with phenylenediamine, and transmission electron microscopy sections were stained with lead and uranyl acetate.

\section{Results}

In all TA-injected eyes, the drug crystals settled within the cortical vitreous overlying the inferior midperipheral retina as a white mass. Its volume became progressively smaller, but the shrinkage was slow, remaining visible on day 14 . Two eyes $(4 \mathrm{mg}$ and 8 $\mathrm{mg}$ ) developed a mild anterior chamber reaction that resolved within 1 week. Another eye $(8 \mathrm{mg})$ developed cataract due to accidental touch of the anterior lens capsule with the needle during paracentesis. No vitreous cells or retinal lesions such as retinal whitening, hemorrhage, or pigmentary changes were noted.

Eyes injected with $0.5 \mathrm{mg}$ and $1 \mathrm{mg}$ of TA did not show any morphologic change during light microscopy, as well as eyes injected with vehicle (Fig. 1A) and saline. However, eyes injected with $4 \mathrm{mg}, 8 \mathrm{mg}$, 

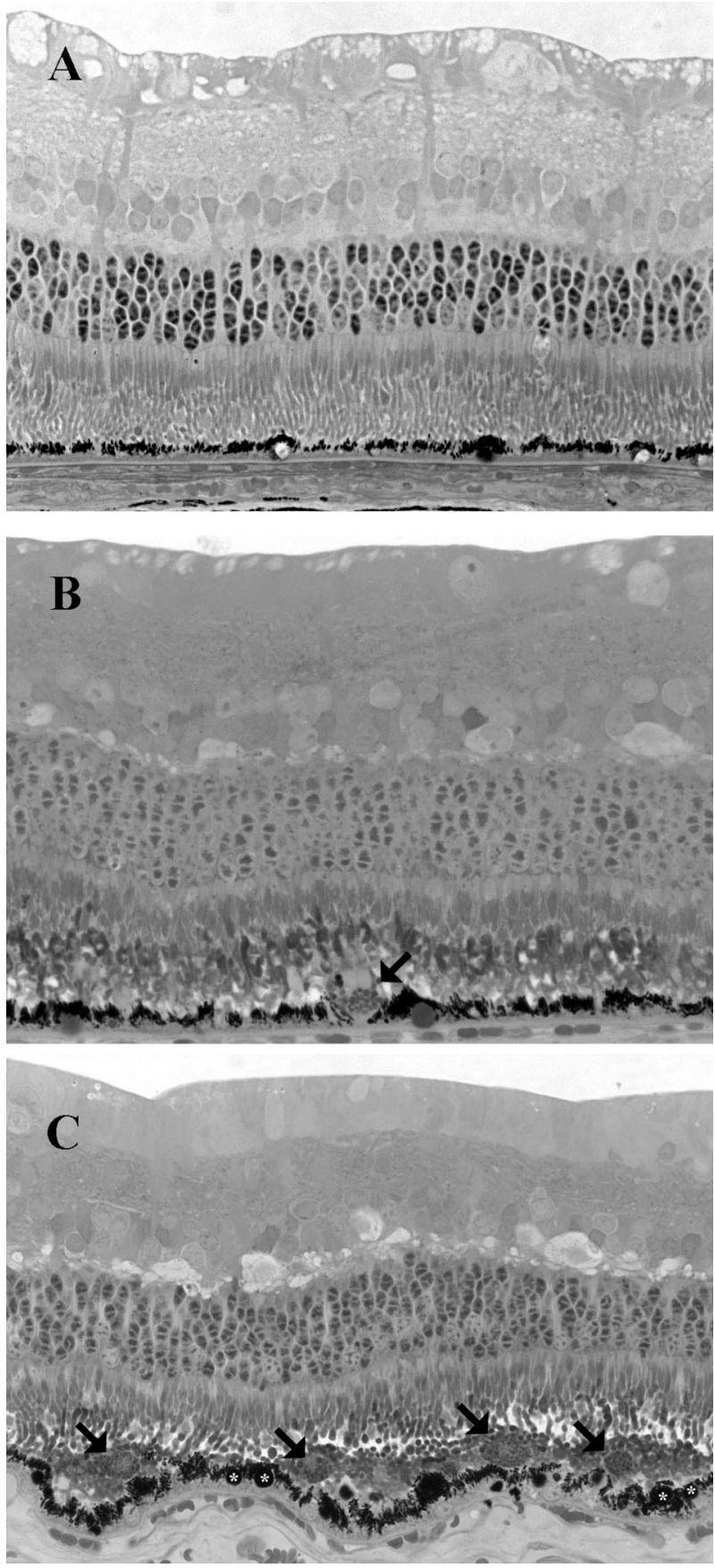

Fig. 1. Light micrographs 14 days after single intravitreal injection of vehicle (A) and of $4 \mathrm{mg}(\mathbf{B})$ and $20 \mathrm{mg}(\mathbf{C})$ of triamcinolone acetonide. A, Well preserved retinal morphology. B, Macrophage-like cell (arrow) on the retinal pigment epithelium (RPE) surface. C, Increased number of macrophage-like cells (arrows), prominent clustering of pigment granules, and enlarged lipid droplets in the RPE cells (asterisks) (stain, phenylenediamine; original magnification, $\times 400$ ).

and $20 \mathrm{mg}$ of TA had dose-dependent changes in the outer retina, such as loss of photoreceptor outer segments and disorganization of the outer segment layer, with macrophage-like cells in the subretinal space,

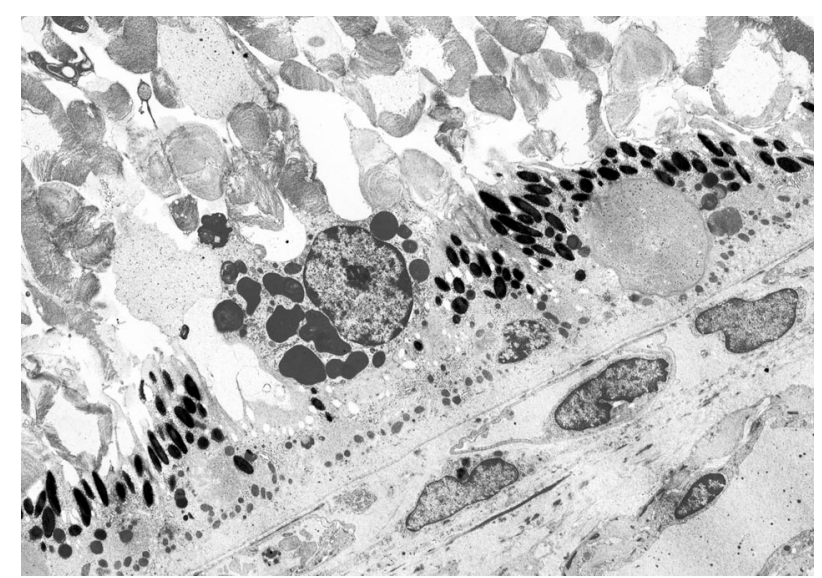

Fig. 2. Electron micrograph 14 days after single intravitreal injection of $4 \mathrm{mg}$ of triamcinolone acetonide. Disruption of photoreceptor outer segments with necrotic cellular debris within the subretinal space and a macrophage in the subretinal space with lamellar inclusions (original magnification, $\times 1,600)$.

particularly in areas with increased outer segment disorganization (Fig. 1, B and C). Retinal pigment epithelium (RPE) cells appeared hypertrophic, with increased pigment granules clustered in the cytoplasm. Amorphous material was in the subretinal space (Fig. 1, B and C). These findings were more evident in eyes injected with $20 \mathrm{mg}$ of TA. In addition, RPE cells of 20-mg injected eyes displayed abundant large oil droplets (Fig. 1C).

Transmission electron microscopy confirmed these findings. Ultrastructures of the eyes injected with 0.5 $\mathrm{mg}$ and $1 \mathrm{mg}$ of TA, vehicle, and saline were normal. However, 4-mg-, 8-mg-, and 20-mg-injected eyes had disruption of photoreceptor outer segments with necrotic cellular debris within the subretinal space. Macrophages in the subretinal space had lamellar and homogeneous inclusions (Fig. 2), and large lipid droplets were seen in the RPE cells. The inner retina appeared normal. In eyes injected with $20 \mathrm{mg}$ of TA, photoreceptor outer segment disruption with loss of the photoreceptor/RPE interdigitation was prominent; clusters of hyperplastic and hypertrophic RPE cells packed with pigment granules and large oil droplets were seen (Fig. 3A). Macrophages displayed increased cytoplasmic inclusions (Fig. 3B).

\section{Discussion}

Recent reports and presentations have shown widespread use of intravitreal TA injections despite lack of convincing safety data as well as randomized clinical trials of long-term efficacy. In this study, we analyzed the morphologic effects of single intravitreal injections of Kenalog-40 (the TA preparation used in the United States) at doses commonly used in clinical 

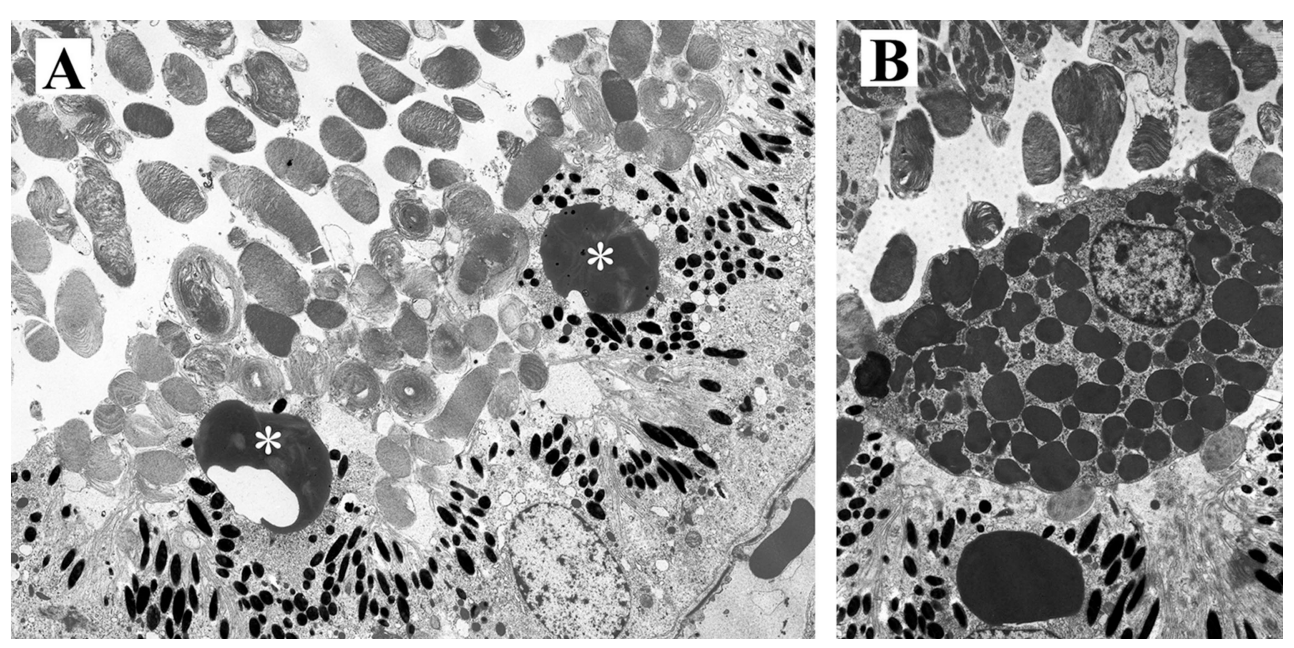

Fig. 3. Electron micrographs 14 days after single intravitreal injection of $20 \mathrm{mg}$ of triamcinolone acetonide. A, Photoreceptor outer segment disruptions are seen in association with loss of the photoreceptor/retinal pigment epithelium (RPE) interdigitation. The RPE cells show large lipid droplets (asterisks) and pigment granules (original magnification, $\times 1,600)$. B, A macrophage-like cell packed with cytoplasmic inclusions is shown (original magnification, $\times 2,400$ ). practice. Our study suggests that TA is toxic to rabbit retina in doses as low as $4 \mathrm{mg}$. Eyes injected with doses of $4 \mathrm{mg}, 8 \mathrm{mg}$, and $20 \mathrm{mg}$ of TA showed dose-dependent structural changes in the outer retina, such as photoreceptor outer segment disruption, accumulation of amorphous cellular debris, and migration of macrophage-like cells in the subretinal space. Hyperplastic and hypertrophic RPE cells with increased pigment granules and large lipid droplets were also present in these eyes.

In our laboratory, we previously demonstrated retinal toxicity in pigmented rabbits after intravitreal injections of dexamethasone. ${ }^{22}$ With $400 \mu \mathrm{g}$, transient Müller cell swelling was observed. However, with larger doses, permanent photoreceptor outer segment disintegration with accumulation of amorphous granules on the surface of the RPE layer was found. Müller cells were suggested as the primary site of damage. This work supported earlier findings of Shimada and Matsui, ${ }^{23}$ who showed retinal degeneration confined to the inferior region of the fundus after a $10-\mathrm{mg}$ dexamethasone injection.

This study demonstrated that doses as low as $4 \mathrm{mg}$ of TA injected in the vitreous produced morphologic changes in rabbit retina. Other than a meeting presentation (American Society of Retina Specialists, 2003; 602), none of the few reported studies showed retinal toxicity with doses as high as $4 \mathrm{mg} .{ }^{18-21,24-26} \mathrm{McCuen}$ et $\mathrm{al}^{18} \mathrm{did}$ not find histologic or functional signs of retinal toxicity after injection of $1 \mathrm{mg}$ of TA in pigmented rabbit eyes in a 3-month follow-up. Hui et al ${ }^{19}$ injected $1 \mathrm{mg}, 2 \mathrm{mg}$, and $4 \mathrm{mg}$ of TA and did not find any signs of toxicity with both light microscopy and electron microscopy. In our study, we confined the tissue analysis to the inferior retina, because after intravitreal injection the drug settles inferiorly, where maximal concentration is expected. This may explain why we found toxic effects with $4 \mathrm{mg}$ of TA while other previously reported studies did not. Another difference among this study and the others was the time point (14 days in our study vs. 3 months ${ }^{18}$ and 28 days ${ }^{19}$ ). Although the follow-up in this study was shorter and we examined only one time point, it seems unlikely that the findings described here could be reversible in nature.

Kivilcim et al $^{21}$ also studied the retinal toxicity of 1 $\mathrm{mg}, 2 \mathrm{mg}$, and $4 \mathrm{mg}$ of TA in vitrectomized, siliconefilled albino rabbit eyes and showed no morphologic or electroretinographic changes with these doses. In this case, comparison with our results is inappropriate because of differences of pigmentation between the rabbit species used as well as because vitrectomy changes the dynamics and pharmacokinetic of the drug inside the eye. Another difference is the time point: Kivilcim et $\mathrm{al}^{21}$ killed the animals when no drug was visible in the vitreous cavity, while we killed the animals 14 days after the injection.

Our results show damage to the outer retina by TA. In doses as low as $4 \mathrm{mg}$ of TA, disorganization of the photoreceptor outer segments of different degrees was noted. Photoreceptor injury leads to increased shedding of cellular debris into the subretinal space, and with the accumulation of necrotic cellular debris, the macrophages migrate into the subretinal space. In addition, it is possible that the RPE cells are also damaged, as suggested by the in vitro experiments of Yeung et al. ${ }^{27}$ Furthermore, TA may produce loss of the crucial interdigitation between the outer segments and the apical RPE microvilli, followed by outer segment degeneration. TA may also have an inhibitory effect on the RPE phagocytosis and lysosomal activity, as demonstrated by Uyama et al28 in cultured RPE cells; the increased number of large lipid droplets seen in the 20-mg treated eyes in our study may have been 
caused by the decreased lysosomal activity in the RPE cells.

Some investigators believe that retinal toxicity associated with TA may be due to its vehicle, benzyl alcohol. ${ }^{18,29}$ In our model, eyes injected with vehicle alone did not show any toxicity. Similarly, Hida et al ${ }^{30}$ and Morrison et al (Association for Research in Vision and Ophthalmology, 2004; 1917) demonstrated no retinal toxicity of benzyl alcohol at the concentration used in clinical practice, reinforcing our findings. Hida et $\mathrm{al}^{30}$ also showed no associated toxicity with twice the concentration of benzyl alcohol found in the Kenalog suspension, and Morrison et al (Association for Research in Vision and Ophthalmology, 2004; 1917) showed toxicity only with higher concentrations ( $>3.3$ times). In addition, Yeung et $\mathrm{al}^{27}$ did not detect any in vitro toxic effect of benzyl alcohol on RPE cells. Interestingly, in a recent correspondence by Rodriguez-Coleman et al, ${ }^{31}$ benzyl alcohol was reported to partition with triamcinolone crystals as a result of its preference for a lipophilic environment. Thus, a better control to separate the effects of benzyl alcohol from TA would have been a preparation containing the exact concentration of benzyl alcohol as determined by high-performance liquid chromatography from the sedimented suspensions of TA, the procedure used in our study to prepare 8 -mg and 20-mg injections.

This study was designed bearing two important issues. First, we used pigmented rabbits because it is known that melanin granules have affinity for certain lipophilic drugs. ${ }^{32} \mathrm{~A}$ drug dose that is safe in an albino eye may show detrimental effects when applied to a pigmented eye. Therefore, the use of pigmented rabbits for drug toxicity studies may be more relevant to the human eye. Second, we confined our tissue analysis to the inferior retina, where maximal drug concentration is expected after intravitreal injection. We were not able to affirm that toxic changes are diffuse on the retina, because we only analyzed a small part of the inferior retina where the drug was confined, but the changes we found were throughout the $5 \times 5$-mm fragments.

A possible critique of this study may be that we did not use full-field electroretinography in our study. Although electroretinography is a useful test in ocular pharmacology, our personal experience is that this examination presents variable results when trying to detect subtle toxicity changes or localized retinal changes confined to the drug depot. Our focus was to show morphologic changes.

Another limitation of our study is that the actual TA concentration was not measured before injection, and when dealing with a suspension of crystals that settle rapidly, the actual injected doses may not be exactly the targeted doses. In addition, when preparing the 8-mg and 20-mg doses, we did not account for the small loss of steroid crystals in the ejected supernatants. In our study, it was our goal to use a preparation method favored in clinical practice, and we were also aware from the report by Rodriguez-Coleman et $\mathrm{al}^{31}$ that the method used in our study, sedimentation without filtration, produced the closest final dose to the targeted dose. The more sophisticated filtration methods actually resulted in variable and consistently lower doses than the predicted range. This was also confirmed by Kreissig et al (Association for Research in Vision and Ophthalmology, 2005; 4731).

This study showed dose-related toxic effects of TA in rabbit outer retina with doses as low as $4 \mathrm{mg}$, while lower doses, such as $0.5 \mathrm{mg}$ and $1 \mathrm{mg}$, did not cause morphologic retinal changes. Needless to say, there are many differences, such as species differences, ocular volume differences, and presence of intraocular inflammation, to be taken into consideration before we can apply these data to clinical practice. The rabbit vitreous volume is one half to one third of that of humans, and it is likely that a higher localized concentration is further achieved with the drug pocketed within the overlying formed cortical vitreous in the rabbit eyes. Currently, $4 \mathrm{mg}$ is the most commonly used dose of TA in intravitreal injections, but clinicians have used higher doses. It is possible that $4 \mathrm{mg}$ in the vitreous cavity of an inflamed human eye is equivalent to $0.5 \mathrm{mg}$ or $1 \mathrm{mg}$ in the rabbit eyes and is thus safe. Our data should caution use of higher doses of TA and frequent repeated injections until further long-term retinal toxicity studies are performed.

Key words: antiinflammatory agents, corticosteroids, intravitreal drug delivery.

\section{References}

1. Martidis M, Duker JS, Greenberg PB, et al. Intravitreal triamcinolone for refractory diabetic macular edema. Ophthalmology 2002;109:920-927.

2. Massin P, Audren F, Haouchine B, et al. Intravitreal triamcinolone acetonide for diabetic diffuse macular edema: preliminary results of a prospective controlled trial. Ophthalmology 2004;111:218-225.

3. Park CH, Jaffe GJ, Fekrat S. Intravitreal triamcinolone acetonide in eyes with cystoid macular edema associated with central retinal vein occlusion. Am J Ophthalmol 2003;136: 419-425.

4. Conway MD, Canakis C, Livir-Rallatos C, Peyman GA. Intravitreal triamcinolone acetonide for refractory chronic pseudophakic cystoid macular edema. J Cataract Refract Surg 2003;29:27-33.

5. Antcliff RJ, Spalton DJ, Stanford MR, et al. Intravitreal triamcinolone for uveitic cystoid macular edema: an optical 
coherence tomography study. Ophthalmology 2001;108:765772.

6. Challa JK, Gillies MC, Penfold PL, et al. Exudative macular degeneration and intravitreal triamcinolone: 18 months follow-up. Aust N Z J Ophthalmol 1998;26:277-281.

7. Gillies MC, Simpson JM, Luo W, et al. A randomized clinical trial of a single dose of intravitreal triamcinolone acetonide for neovascular age-related macular degeneration: one-year results. Arch Ophthalmol 2003;121:667-673.

8. Jonas JB, Hayler JK, Panda-Jona S. Intravitreal injection of crystalline cortisone as adjunctive treatment of proliferative vitreoretinopathy. Br J Ophthalmol 2000;84:1064-1067.

9. Martidis A, Duker JS, Puliafito CA. Intravitreal triamcinolone for refractory cystoid macular edema secondary to birdshot retinochoroidopathy. Arch Ophthalmol 2001;119:13801383 .

10. Jonas JB. Intraocular availability of triamcinolone acetonide after intravitreal injection. Am J Ophthalmol 2004;137:560 562.

11. Ziada G, el-Haddad S, Fatouh M, et al. Radionuclide study of the blood ocular barrier. Eur J Drug Metab Pharmacokinet 1985;10:325-328.

12. McGhee CN, Dean S, Danesh-Meyer H. Locally administered ocular corticosteroids: benefits and risks. Drug Saf 2000;25:33-55.

13. Gillies MC, Simpson JM, Billson FA, et al. Safety of an intravitreal injection of triamcinolone: results from a randomized clinical trial. Arch Ophthalmol 2004;122:336-340.

14. Kaushik S, Gupta V, Gupta A, et al. Intractable glaucoma following intravitreal triamcinolone in central retinal vein occlusion. Am J Ophthalmol 2004;137:758-760.

15. Moshfeghi DM, Kaiser PK, Scott IU, et al. Acute endophthalmitis following intravitreal triamcinolone acetonide injection. Am J Ophthalmol 2003;136:791-796.

16. Nelson ML, Tennant MT, Sivalingam A, et al. Infectious and presumed noninfectious endophthalmitis after intravitreal triamcinolone acetonide injection. Retina 2003;23:686-691.

17. Jonas JB, Kreissig I, Degenring RF. Retinal complication of intravitreal injections of triamcinolone acetonide. Graefes Arch Clin Exp Ophthalmol 2004;242:184-185.

18. McCuen BW 2nd, Bessler M, Tano Y, et al. The lack of toxicity of intravitreally administered triamcinolone acetonide. Am J Ophthalmol 1981;91:785-788.

19. Hui YN, Liang HC, Cai YS, et al. Corticosteroids and daunomycin in the prevention of experimental proliferative vitreoretinopathy induced by macrophages. Graefes Arch Clin Exp
Ophthalmol 1993;231:109-114.

20. Danis PR, Bingaman DP, Yang Y, Ladd B. Inhibition of preretinal and optic nerve head neovascularization in pigs by intravitreal triamcinolone acetonide. Ophthalmology 1996; 103:2099-2104.

21. Kivilcim M, Peyman GA, El-Dessouky ES, et al. Retinal toxicity of triamcinolone acetonide in silicone-filled eyes. Ophthalmic Surg Lasers 2000;31:474-478.

22. Kwak HW, D'Amico DJ. Evaluation of the retinal toxicity and pharmacokinetics of dexamethasone after intravitreal injection. Arch Ophthalmol 1992;110:259-266.

23. Shimada H, Matsui M. Effect of intravitreal steroid injection on rabbit eye. Acta Soc Ophthalmol Jpn 1989;93:501-510.

24. Tano Y, Chandler D, Machemer R. Treatment of intraocular proliferation with intravitreal injection of triamcinolone acetonide. Am J Ophthalmol 1980;90:810-816.

25. Chandler DB, Rozakis G, de Juan E Jr, Machemer R. The effect of triamcinolone acetonide on a refined experimental model of proliferative vitreoretinopathy. Am J Ophthalmol 1985;99:686-690.

26. Ishibashi T, Miki K, Sorgente N, et al. Effects of intravitreal administration of steroids on experimental subretinal neovascularization in the subhuman primate. Arch Ophthalmol 1985;103:708-711.

27. Yeung CK, Chan KP, Chiang SW, et al. The toxic and stress responses of cultured human retinal pigment epithelium (ARPE19) and human glial cells (SVG) in the presence of triamcinolone. Invest Ophthalmol Vis Sci 2003;44:52935300.

28. Uyama M, Sugasawa K, Kishimoto N, Kawahara S. Effect of corticosteroid on porcine retinal pigment epithelial cells in culture-2. Effects on phagocytosis and lysosomal activity. J Jpn Ophthalmol Soc 2000;104:86-90.

29. Roth DB, Cheieh J, Spirn MJ, et al. Noninfectious endophthalmitis associated with intravitreal triamcinolone injection. Arch Ophthalmol 2003;121:1279-1282.

30. Hida T, Chandler D, Arena JE, Machemer R. Experimental and clinical observations of the intraocular toxicity of commercial corticosteroid preparations. Am J Ophthalmol 1986; 101:190-195.

31. Rodriguez-Coleman H, Peng Y, Kim H, et al. Intravitreal injection of triamcinolone for diffuse macular edema. Arch Ophthalmol 2004;122:1085-1086.

32. Dayhaw-Barker P. Retinal pigment epithelium melanin and ocular toxicity. Int J Toxicol 2002;21:451-454. 